International Journal of Engineering \& Technology, $7(1.1)(2018) 525-529$
International Journal of Engineering \& Technology
SPC
Website: www.sciencepubco.com/index.php/IJET
Research paper

\title{
Design and analysis of square shaped serrated patch antenna for ultra-wideband applications with single rejection band
}

\author{
P Saleem Akram, B T P Madhav, G. Jeevana Sravya, V. Sudhakar, \\ G. Lakshmi Sirisha, Ch. Mounika, M. Venkateswara Rao \\ ALRC, Department of ECE, Koneru Lakshmaiah Education Foundation, AP, India \\ *Corresponding authorE-mail: btpmadhav@kluniversity.in
}

\begin{abstract}
This article studies about the design and analysis of serrated patch antenna with a slot at the ground with microstrip line feed. Comparative analysis has been carried in five and ten serrated patches at top and side edges of the square patch. All design iterations have been carried out using commercially equipped tool HFSS 13. For bandwidth enhancement a slot has been placed at the ground in all iterations in common, later the return loss and gain have been analyzed and compared for all models. Finally, the proposed modal consists of ten serrations at the three edges of the square patch where it works on the ultrawide band region with high gain when compared to all models. The proposed antenna has its applications at WiMAX, WLAN 802.11, LTE 42/43 bands and works in the region of ultrawide band $(3.1 \mathrm{GHz}-10.6 \mathrm{GHz})$. and having rejection at $5-6 \mathrm{GHz}$
\end{abstract}

Keywords: Serrated patch, ultrawideband(UWB), HFSS 13.

\section{Introduction}

Now-a-days, wireless technologies had a rapid growth so that antenna must be in a compact size and should have a wide bandwidth. Microstrip patch antenna is advantageous because of its simple structure, stable gain, low profile, low cost [1] and it can support multiple frequency bands which can be dual or triple. Microstrip antennas are used in airborne and spacecraft systems because there requires dielectric cover over the radiating element to give protection against the heat, environment and physical damage [9]. A patch antenna consists of radiating patch on one side and ground plane on the other side, which is fed with microstrip line. The width of conducting strip line is smaller as compared to patch used. The dielectric material of thick size and with lower dielectric constant will improve the antenna performance [3]. As the microstrip patch antenna is of small size, the wideband characteristics can be achieved with the appropriate choice of parameter. The monopole antenna is used for improvement in the frequency bandwidth and the radiation properties of the antenna [6]. A simple slot on the ground plane under the fed line has been used as the base antenna for maximum utilization of bandwidth and to improve the impedance matching of the antenna so that it operates in UWB range [2]. Ultrawideband is a technology that utilizes very low energy level for short-range and covers a large portion of radio spectrum [5]. The ground slots can be of many shapes such as rectangular, circular, hexagonal etc. out of which we have used rectangular shaped ground slot [1]. In the design of microstrip fed monopole antenna the use of serrations has enhanced the bandwidth. A serrated antenna has a saw-toothed shape with material being cut is in contact with some small points and this serrated edge are preferred when using tough and thick materials [8]. A part of edges on the square patch are truncated to get a serrated edged square patch the antenna is designed by placing serrations on single, double, three sides. Ten serrations are examined in this work by changing the number of serrated edges. The serrations are used to improve the isolation and radiation characteristics of the elements [10]. In this paper, attempts are made by varying number of serrations for the UWB antenna. The performance of antenna is simulated using commercial Electro Magnetic tool (HFSS) [4]. One of the serious issue that hinders the performance of the antenna is the isolation between the two feed locations, input and output. Decimating this coupling between the feed locations represents a significant improvement in the performance of antenna because it eliminates the unwanted feedback, providing a stable output, thus, improving overall performance of the antenna [11]. The result of study on the effect the using different number of serrations to evaluate the performance of an UWB antenna in terms of impedance bandwidth, return loss, gain (peak and+ average).

\section{Antenna design}

A compact microstrip-fed UWB monopole antenna with a ground slot which is used as a reference antenna in our study. The antenna is designed on FR4 substrate with a thickness of $1.6 \mathrm{~mm}$. In this antenna we used a square radiator patch printed on one side of the substrate has a length of $\mathrm{Lp}$, on other side of ground is slotted with a rectangular slot and which is fed by a microstrip line with a length of Lf and a width of Wf.. A small cut of rectangular slot on the upper edge of the ground plane with a dimensions of Lrec $x$ Hrec and ground plane with $\mathrm{Lg} \times \mathrm{W}$ which is printed on other side of the substrate. The overall antenna occupies area of $\mathrm{L} \times \mathrm{W}$. In square radiator patch we used serration method in two different ways one is by 5 serrations and other one is by 10 serrations. In 5 serrations they are categorized in upper side of the square patch, 
both sides of the square patch, and three sides of the square patch, and 10 serrations are also categorized in similar manner.

\subsection{Serrations}

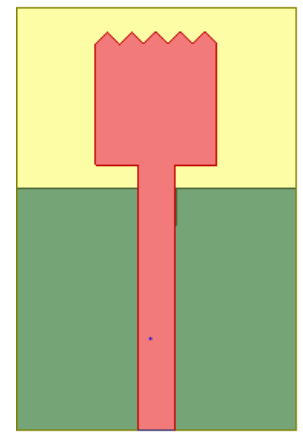

(a)

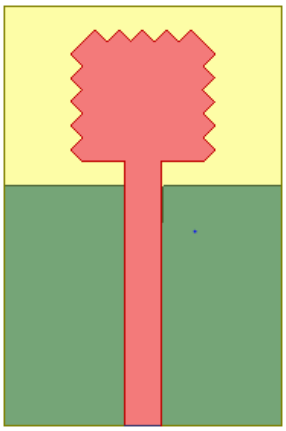

(c)

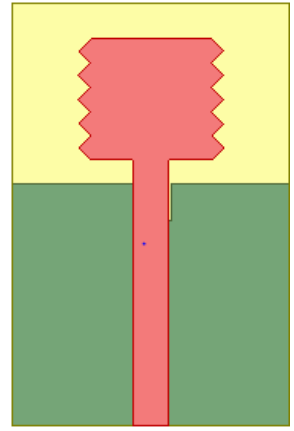

(b)

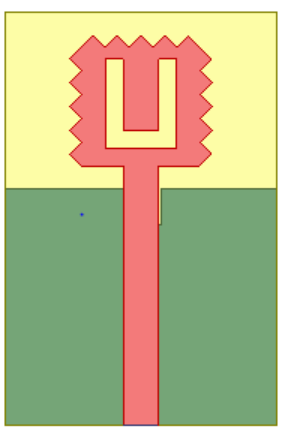

(d)
Fig 1: a) Top edge of square patch with 5 serrations. b) Opposite edges of square patch with 5 serrations. c) Three edges of square patch with 5 serrations d) Three edges of square patch with $\mathrm{U}$-shape and 5 serrations on each edge.

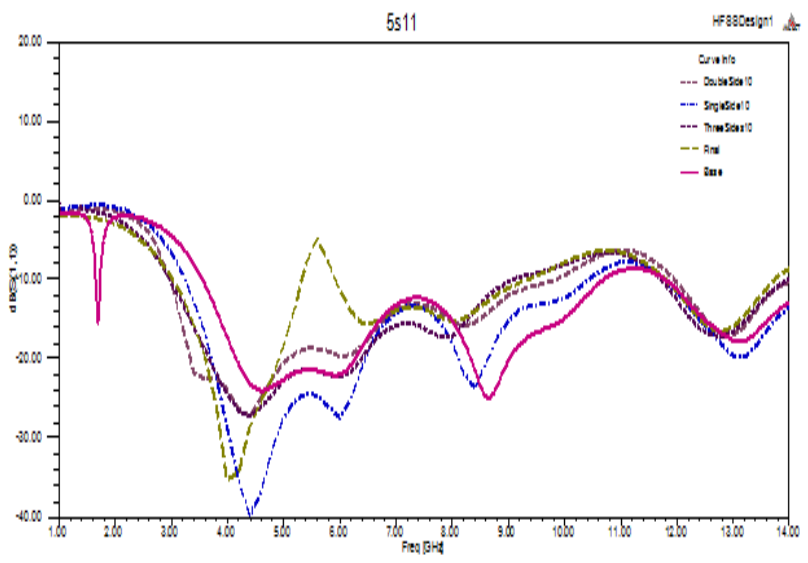

Fig 2: Return loss of 5 Serrated Patch Antenna

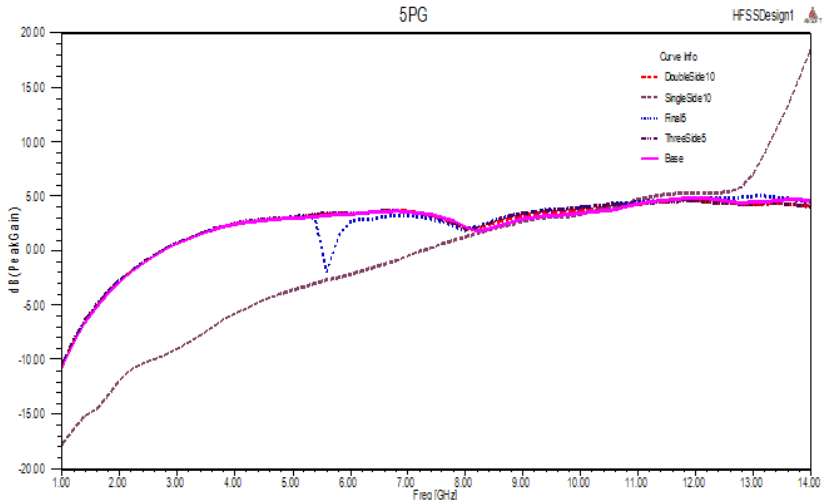

Fig 3: Peak Gain of 5 Serrared Patch Antenna

The simulation study has been carried out by using 5 serrations in different iterations. In first iteration upper edge of the square patch is serrated and we obtained a return loss of $3.21-10.37 \mathrm{GHz}$ which comes under $4 \mathrm{G}$ (LTE) of cellular communication and its applications are mainly WIMAX, LTE42/43, WLAN 802.11a/n, upper WLAN, 5G, DSRC, V2V V2I 802.11p and with a peak gain of 4.97.In second iteration two opposite sides of the square patch is serrated and return loss of $2.97-9.76 \mathrm{GHz}$ is obtained which has applications as a) and with a peak gain of 3.73. In third iteration three sides of the square patch is serrated and return loss of 2.93 $8.99 \mathrm{GHz}$ is obtained which has applications as b) and with a peak gain of 5.07.In fourth iteration three sides of the square patch is serrated with a $U$ shape on the patch. The return loss of 3.08$5.3 \mathrm{GHz}$ and $6.01-9.9 \mathrm{GHz}$ is obtained. Thus, we can infer that the antenna operates in dual bands. It has applications as c) and a peak gain of 5 .

\subsection{Serrations}

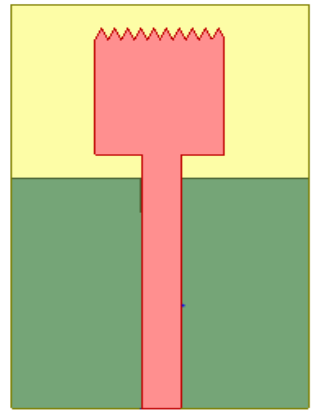

(a)

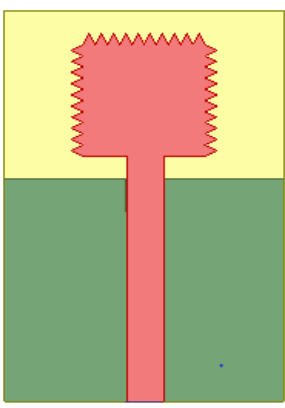

(c)

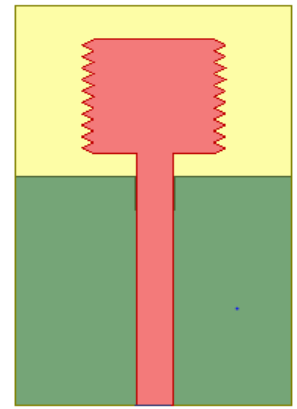

(b)

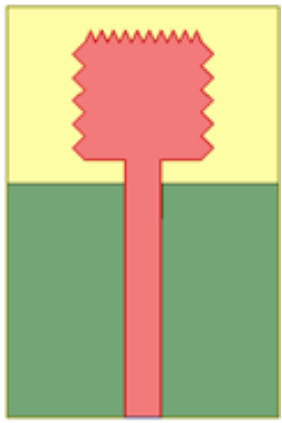

(d)
Fig 4: a) Top edge of square patch with 10 serrations. b) Opposite edges of square patch with 10 serrations on each edge.c) Three edges of square patch with 10 serrations on each edged) Opposite edges of square patch with 5 serrations on each edge and remaining edge with 10 serrations 


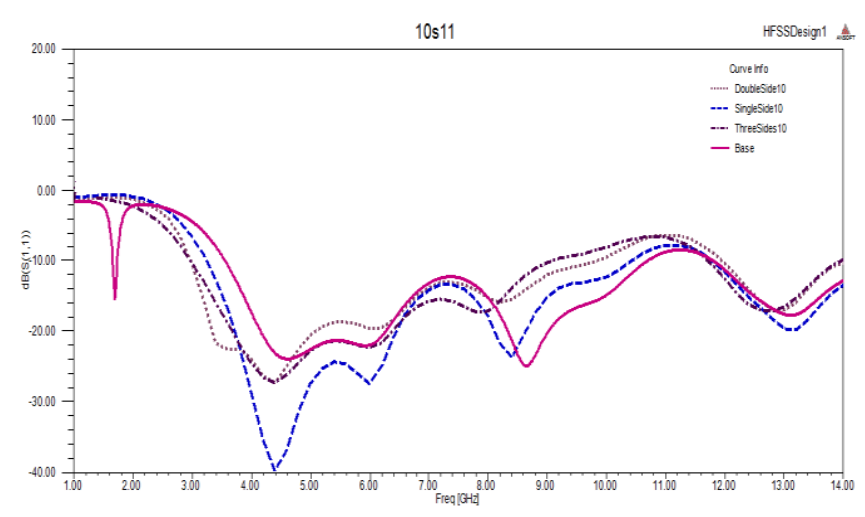

Fig 5: Return loss of 10 Serrated Patch Antenna

The simulation study has been carried out by using 10 serrations in different iterations.In first iteration upper edge of the square patch is serrated and we obtained a return loss of 3.09$10.5 \mathrm{GHz}$ which comes under $4 \mathrm{G}(\mathrm{LTE})$ of cellular communication and its applications are mainly WiMAX, LTE42/43, WLAN 802.11a/n, upper WLAN, 5G, DSRC, V2V V2I 802.11p and with a peak gain of 5.28.In second iteration two opposite sides of the square patch is serrated and return loss of $3.19-9.98 \mathrm{GHz}$ is obtained which has applications as a)and with a peak gain of 4.66 . In third iteration three sides of the square patch is serrated and return loss of $3.17-9.78 \mathrm{GHz}$ is obtained which has applications as b) and with a peak gain of 4.6 .

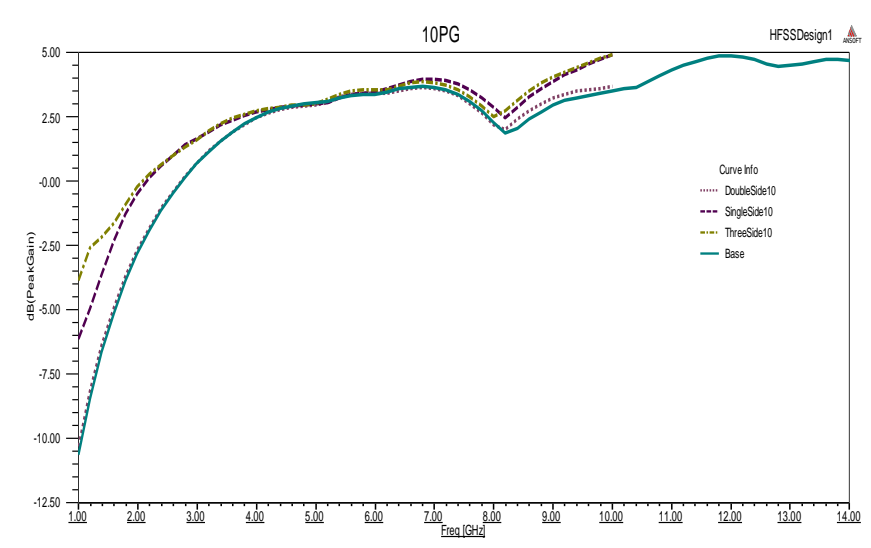

Fig 6: Peak gain of 10 Serrated Patch Antenna.

\subsection{Base antenna and Proposed antenna}

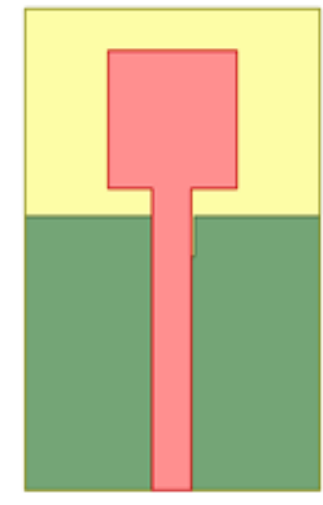

(a)

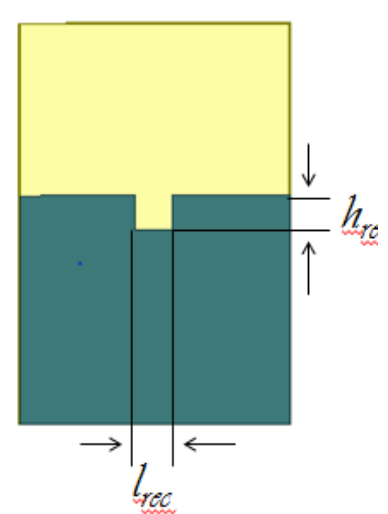

(b)

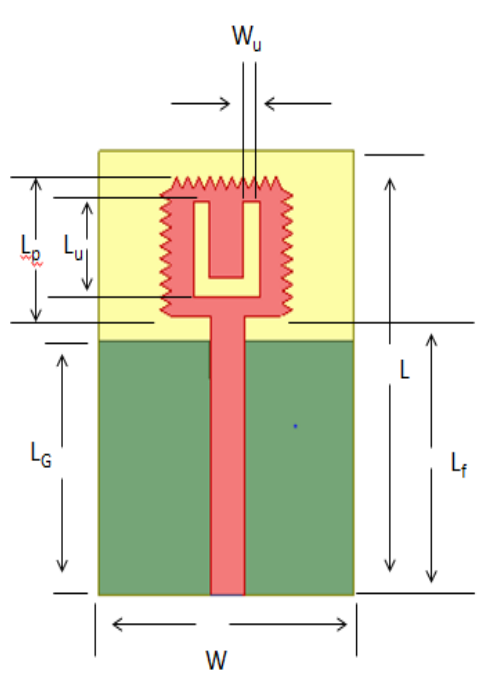

(c)

Fig 7: a) Base antenna with a ground slot's) Back view of proposed antenna's) Front view of proposed antenna.

The base antenna has a square radiated patch with a rectangular slot on the ground plane. The simulation study has been carried out to estimate the return loss and gain. The return loss of 1.68$1.72 \mathrm{GHz}$ and $3.56-10.65 \mathrm{GHz}$ is obtained which has dual bandwidth. Its applications are mainly LTE42/43, WLAN $802.11 \mathrm{a} / \mathrm{n}$, upper WLAN, 5G, DSRC, V2V V2I 802.11p, PCS band and with a peak gain of 5.49. In this three sides of the square patch are serrated with a $U$ shape on the patch. The return loss of $2.98-5.29 \mathrm{GHz}, 5.94-9.33 \mathrm{GHz}$ and $11.81-13.7 \mathrm{GHz}$ is obtained. Thus, we can infer antenna operates in triple band. It has applications as WiMAX, LTE42/43, WLAN 802.11a/n, upper WLAN, 5G, DSRC, V2V V2I 802.11p and has a peak gain of 5.18 .

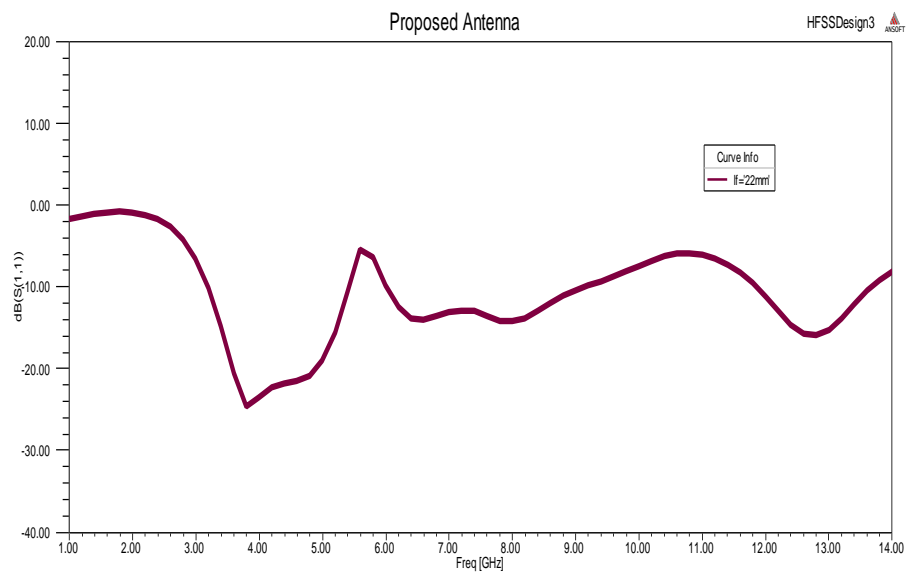

Fig 8: Proposed antenna return loss

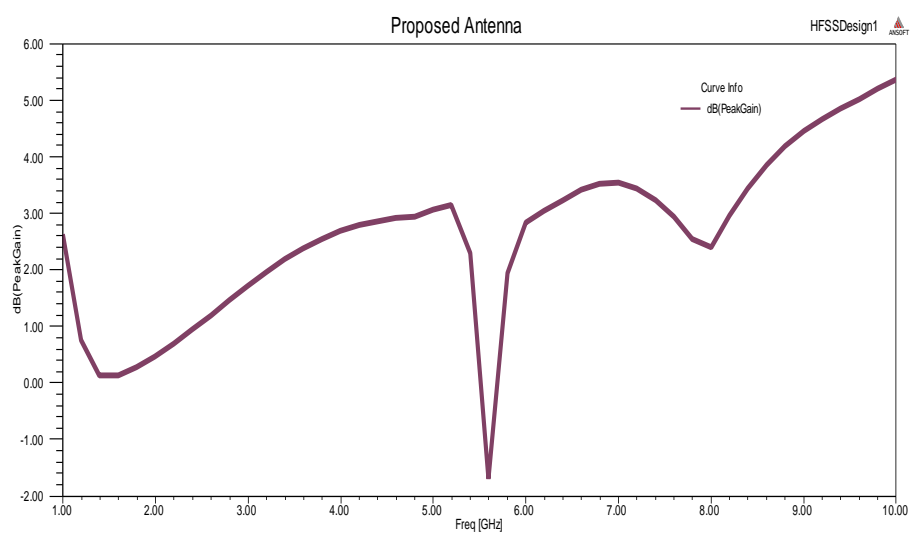

Fig 9: Proposed antenna peak gain vs frequency 


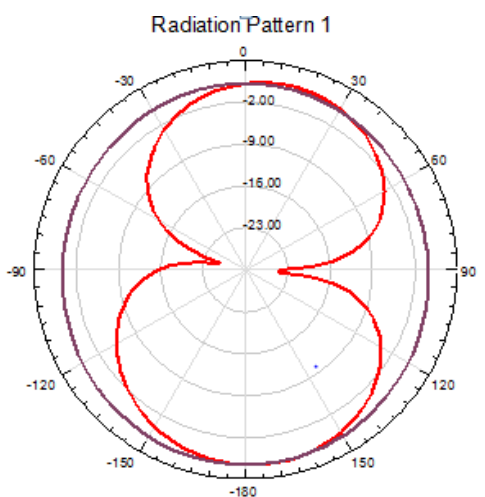

a) At 4.2

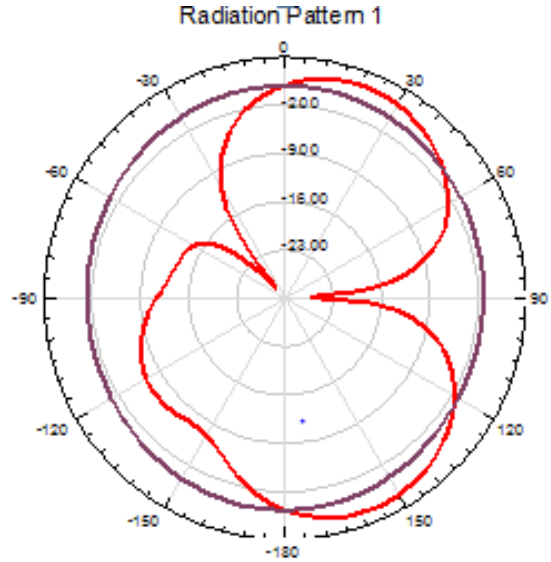

b) At 6.4

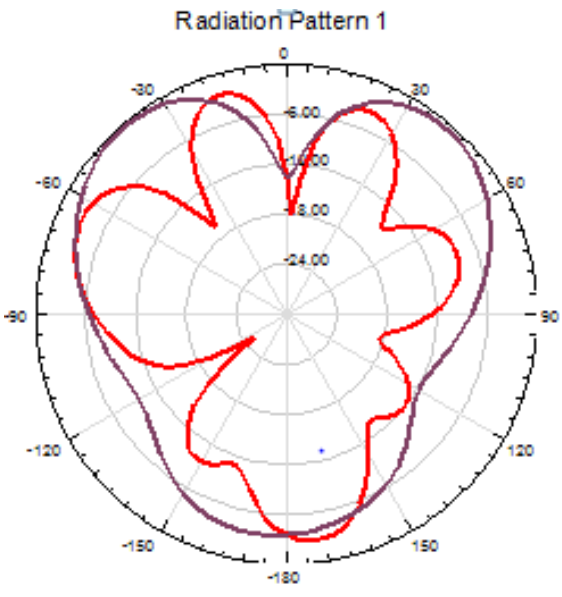

c) At 12.8

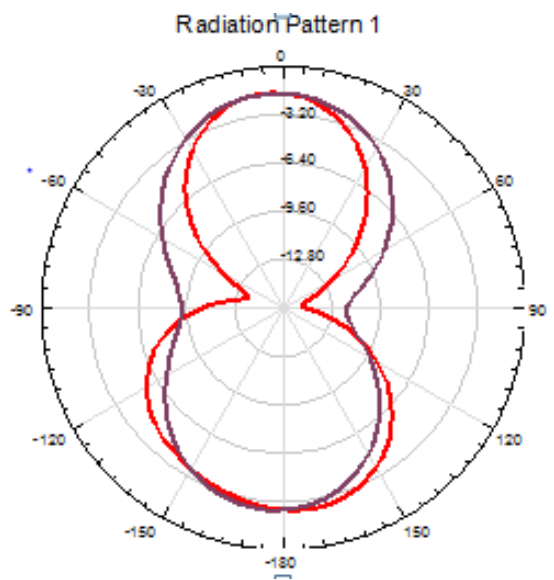

d) At 5.6

Fig 10: Proposed antenna peak gain vs frequency

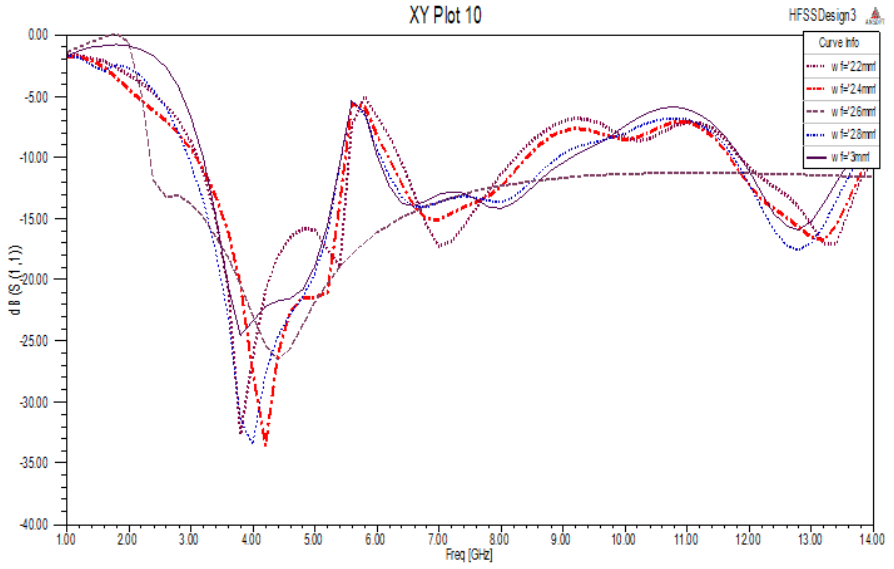

Fig 11: Proposed antenna peak gain vs frequency

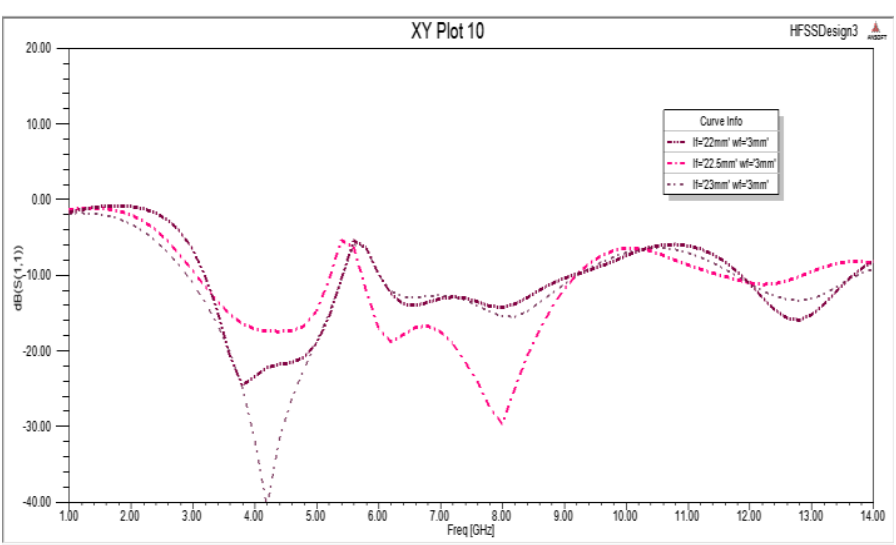

Fig 12: Parametric analysis by changing width of the feed
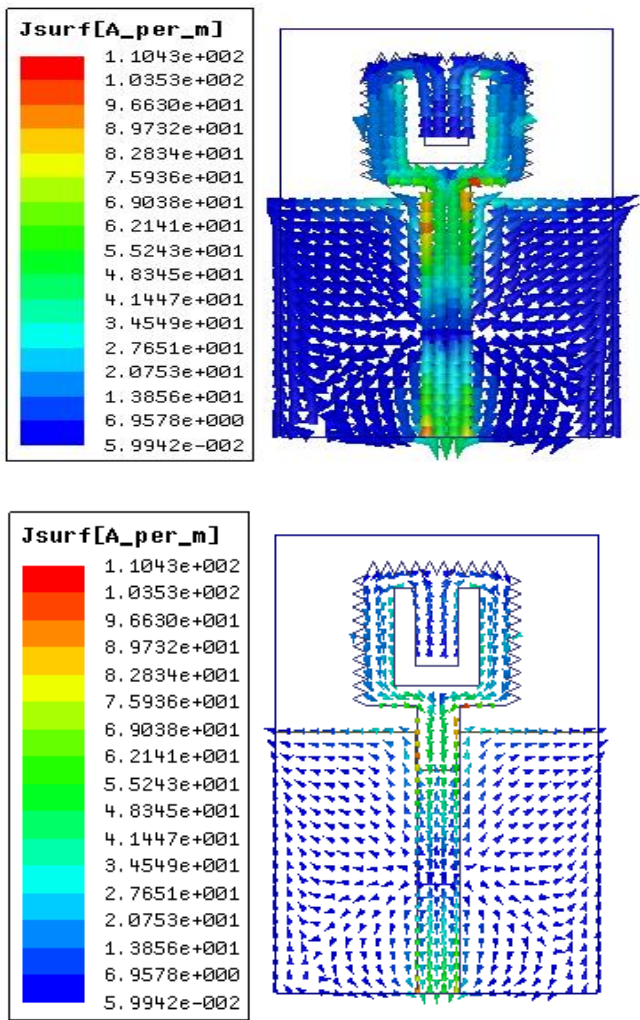

Fig 13: current distributions at $4.3 \mathrm{GHz}$ and $12.8 \mathrm{GHz}$ 


\section{Conclusion}

An Ultra-wideband band notched antenna having ten serrations at the edges of the patch and by placing u-shaped slot on patch middle has been proposed in this article. Comparative analysis has been made on sides of the patch with five and ten serrations. Finally placing a U-shaped slot on the middle of the patch to get the notch characteristics has been seen. Comparative analysis has been carried out using HFSS software. The gain of the proposed antenna is as high as $5 \mathrm{~dB}$ which is most when compares to all models. The proposed antenna works at the ultrawide band region

\section{Acknowledgement}

The authors deeply express their gratitude to ALRC Research Centre, Department of ECE, K L University for their encouragement during this work. Further, we express our gratitude to DST through ECR/2016/000569, FIST SR/FST/ETI-316/2012 and EEQ/2016/000604

\section{References}

[1] Liu, L., Cheung, S. W., \& Yuk, T. I. (2011). Bandwidth improvements using ground slots for compact UWB microstrip-fed antennas. In Progress in Electromagnetics Research Symposium. Electromagnetics Academy. The Journal's web site is located at http://www. piers. org/piers proceedings/.

[2] Babu, M. R., Sarat, K. K., \& Madhav, B. T. P. (2016). Compact serrated notch band MIMO antenna for UWB applications. ARPN Journal of Engineering and Applied Sciences, 11, 4358-4369.

[3] Azim, R., Islam, M. T., Misran, N., Cheung, S. W., \& Yamada, Y. (2011). Planar UWB antenna with multi-slotted ground plane. Microwave and Optical Technology Letters, 53(5), 966-968.

[4] Bhavani, K. V. L., Khan, H., Rao, D. S., Madhav, B. T. P., Reddy, V. R., Monika, M., \& Chand, Y. D. (2016). DUAL BAND NOTCHED PLANAR PRINTED ANTENNA WITH SERRATED DEFECTED GROUND STRUCTURE. Journal of Theoretical \& Applied Information Technology, 88(1).

[5] Ojaroudi, M., Kohneshahri, G., \& Noory, J. (2009). Small modified monopole antenna for UWB application. IET microwaves, antennas \& propagation, $3(5), 863-869$.

[6] Zaker, R., \& Abdipour, A. (2010). A very compact ultrawideband printed omnidirectional monopole antenna. IEEE Antennas and wireless propagation letters, 9, 471-473.

[7] Lee, K. F., \& Luk, K. M. (2011). Microstrip patch antennas. World Scientific.

[8] Pozar, D. M., \& Schaubert, D. H. (Eds.). (1995). Microstrip antennas: the analysis and design of microstrip antennas and arrays. John Wiley \& Sons.

[9] Bahl, I., Bhartia, P., \& Stuchly, S. (1982). Design of microstrip antennas covered with a dielectric layer. IEEE Transactions on Antennas and Propagation, 30(2), 314-318.

[10] Khanna, A., \& Srivastava, D. K. (2014). Serrated edged microstrip patch antenna using N-shaped slot for WLAN/WiMAX/Bluetooth applications. Int. J. Res. Sci. Eng, 3(7), 330-336.

[11] Cung, G., Huff, G. H., \& Bernhard, J. T. (2003). Ground plane edge serrations for improved performance of microstrip active reflectarray elements. IEEE antennas and wireless propagation letters, 2(1), 334-336. 